Company, Novartis, Pfizer, and Takeda, Consultant for: AbbVie, Amgen, Bristol-Myers Squibb, Celgene, Corrona, Eli Lilly, Novartis, Pfizer Inc, Takeda, Consultant for: Abbvie, Amgen, BMS, Celgene, Corrona, Lilly, Novartis, Pfizer, Takeda, Consultant for: Abbvie, Amgen, BMS, Celgene, Corrona, Lilly, Novartis, Pfizer, Takeda, Kaleb Michaud Grant/research support from: Pfizer (within past 2 years), Steve Peterson Shareholder of: Janssen, Employee of: BMS (2000-2002), Janssen (2002-present), Elizabeth Holdsworth Employee of: Adelphi Real World, Chetan Karyekar Shareholder of: J\&J, Employee of: Janssen Scientific Affairs, LLC, Abbott, BMS, Novartis, Nicola Booth Employee of: Adelphi Real World, Jessalyn Kemp Employee of: Adelphi Real World, Soumya D Chakravarty Shareholder of: Johnson \& Johnson, Employee of: Johnson \& Johnson, Shelly Kafka Shareholder of: J\&J, Employee of: J\&J, Laure Gossec Grant/ research support from: AbbVie, BMS, Celgene, Janssen, Lilly, MSD, Novartis-Sandoz, Pfizer, Sanofi, and UCB, Consultant for: AbbVie, Biogen, BMS, Celgene, Janssen, Lilly, MSD, Nordic Pharma, Novartis-Sandoz, Pfizer, Roche, Sanofi, and UCB, Consultant for: L Gossec has received honoraria from Celgene as investigator for this study

DOI: 10.1136/annrheumdis-2019-eular.7428

Table 1. Impact of manifestations on PROs: Adjusted* regression coefficient and p-values

\begin{tabular}{lccc}
\hline $\begin{array}{l}\text { Outcome measure } \\
\text { (N patients with data } \\
\text { available) }\end{array}$ & Manifestation & Coef. & $\begin{array}{c}\text { P } \\
\text { value }\end{array}$ \\
\hline EQ-5D Index (N=771) & & & \\
& Enthesitis & -0.12 & 0.002 \\
& Dactylitis & -0.07 & 0.010 \\
EQ-5D VAS (N=784) & IBP & -0.07 & 0.001 \\
& Sacroiliitis & -0.06 & 0.259 \\
& Enthesitis & -8.86 & 0.013 \\
& Dactylitis & -4.31 & 0.123 \\
HAQ DI (N=744) & IBP & -4.10 & 0.073 \\
& Sacroilitis & -10.19 & 0.043 \\
& Enthesitis & 0.17 & 0.096 \\
PsAID12 (N=750) & Dactylitis & 0.17 & 0.024 \\
& IBP & 0.20 & 0.003 \\
& Sacroilitis & 0.30 & 0.035 \\
WPAI: Productivity (N=485) & Enthesitis & 1.32 & 0.002 \\
& Dactylitis & 1.09 & 0.003 \\
& IBP & 0.47 & 0.060 \\
& Sacroilitis & 0.59 & 0.243 \\
& Enthesitis & 14.40 & 0.034 \\
& Dactylitis & 4.36 & 0.128 \\
& IBP & 4.07 & 0.185 \\
& Sacroilitis & -3.86 & 0.332 \\
\hline
\end{tabular}

${ }^{*}$ Adjusted for age, gender, number of joints affected, time since diagnosis.

\section{FRI0464 EFFECT OF BIOLOGICS ON ENTHESITIS AND DACTYLITIS IN PATIENTS WITH PSORIATIC ARTHRITIS: A SYSTEMATIC REVIEW AND META-ANALYSIS}

WU Dongze ${ }^{1}$, Priscilla C. Wong ${ }^{1}$, James F. Griffith ${ }^{2}$, Lai-Shan Tam ${ }^{1} .{ }^{1}$ The Prince of Wales Hospital, The Chinese University of Hong Kong, Department of Medicine and Therapeutics, Hong Kong, China; ${ }^{2}$ The Prince of Wales Hospital, The Chinese University of Hong Kong, Department of Imaging and Interventional Radiology, Hong Kong, China

Background: Enthesitis and dactylitis are hallmarks for patients with psoriatic arthritis and mechanical injury are common risk factor for enthesitis and dactylitis [1-4]. Biologic disease modifying anti-rheumatic drugs (bDMARDs), including tumor necrosis factor alpha (TNF- $\alpha$ ), interleukin (IL), phosphodiesterase type 4(PDE-4), Janus kinase (JAK) blockers and abatacept have shown efficacy on enthesitis and dactylitis in patients with PsA.

Objectives: The aims of this study are to summarize the efficacy of the bDMARDs on enthesitis and dactylitis in patients with PsA.

Methods: Systematically review of articles published up to Jan 2019 in Medline and Web of Science, and abstracts from the two last EUropean League Against Rheumatism (EULAR) and American College of Rheumatology (ACR) meetings. Primary endpoint was the proportion of patients with resolution of enthesitis or dactylitis from week 12 to 24 . Secondary endpoint was the mean change in different enthesitis score (Leeds Enthesitis Index [LEI, 0-6], Maastricht Ankylosing Spondylitis Enthesitis Score [MASES, 0-13], PSA modified MASES [0-15]) and dactylitis score (Leeds Dactylitis Index [LDI, 0-60], dactylitis severity score [DSS, 0-60], [DSS, 0 20]) from week 12 to 24 . Odds ratio (OR) and standardized mean differ ence (SMD) with $95 \%$ Cls across studies were synthesized.

Results: Nineteen studies (8,208 patients), 10 drugs (adalimumab, infliximab, certolizumab pegol, golimumab, secukinumab, ustekinumab, ixekizumab, abatacept, tofacitinib and apremilast) and 22 treatments were evaluated. Patients treated with bDMARDs were more likely to achieve resolution of enthesitis compared with placebo (OR for pooled: 1.99, 95\% Cl:1.74, 2.27; OR for IL blocker: 2.06, 95\%Cl:1.78, 2.38; OR for abatacept:1.82, 95\%Cl:1.05,3.14; OR for PDE4 blocker:1.67, 95\%Cl:1.14, 2.45) (Figure 1) and have significant improvement in terms of LEI (SMD for pooled: $-2.17,95 \% \mathrm{Cl}$ : $-2.87,-1.46$; SMD for tofacitinib: $-3.83,95 \% \mathrm{Cl}$ : 5.24, -2.43; SMD for TNF blocker: $-1.43,95 \% \mathrm{Cl}$ : $-2.38,-0.48$; SMD for ixekizumab: $-1.47,95 \% \mathrm{Cl}$ : $-2.42,-0.52$; Figure 2A), MASES (SMD fo apremilast: $-1.50,95 \% \mathrm{Cl}:-2.80,-0.21$; Figure 2B), PsA modified MASES (SMD for golimumab: $-0.32,95 \% \mathrm{Cl}$ : $-0.52,-0.12$; Figure $2 \mathrm{C}$ ) compared with placebo. Patients treated with bDMARDs were more likely to achieve resolution of dactylitis compared with placebo (OR for pooled: $3.26,95 \%$ Cl:2.45, 4.33; OR for IL blocker: 3.88, 95\%Cl:2.97, 5.06; OR for abatacept:1.54, 95\% Cl:0.71, 3.34; OR for PDE4 blocker:1.50, 95\%Cl:0.97, 2.33) (Figure 3) and have significant improvement in terms of LDI (SMD for pool: $-1.73,95 \% \mathrm{Cl}$ : $-3.07,-0.40$; SMD for TNF blocker: $-1.67,95 \% \mathrm{Cl}$ : 3.72, 0.38; SMD for ixekizumab: $-1.67,95 \% \mathrm{Cl}$ : $-3.69,0.12$; Figure $4 \mathrm{~A}$ ), DSS [0-60] (SMD for pool: $-2.10,95 \% \mathrm{Cl}$ : $-3.11,-1.10$; SMD for tofacitinib: $-3.39,95 \% \mathrm{Cl}$ : $-4.95,-1.83$; SMD for TNF blocker: $-0.84,95 \% \mathrm{Cl}$ : -1.48 , 0.20; Figure 4B), DSS [0-20] (SMD for apremilast: $-1.20,95 \% \mathrm{Cl}$ : -2.07 , 0.34 ; Figure 4C) compared with placebo.

Conclusion: Biologic DMARDs was effective for PsA patients with enthesiitis and dactylitis. IL blocker is probably the optimal option to consider when patients present with predominant enthesitis and dactylitis

\section{REFERENCES}

[1] Kaeley GS et al, Semin Arthritis Rheum. 2018 Aug;48(1):35-43

[2] Kaeley GS et al, Semin Arthritis Rheum. 2018 Oct;48(2):263-273

[3] Schett $G$ et al, Nat Rev Rheumatol. 2017 Nov 21;13(12):731-741

[4] McGonagle D et al, Nat Rev Rheumatol. 2019 Feb;15(2):113-122

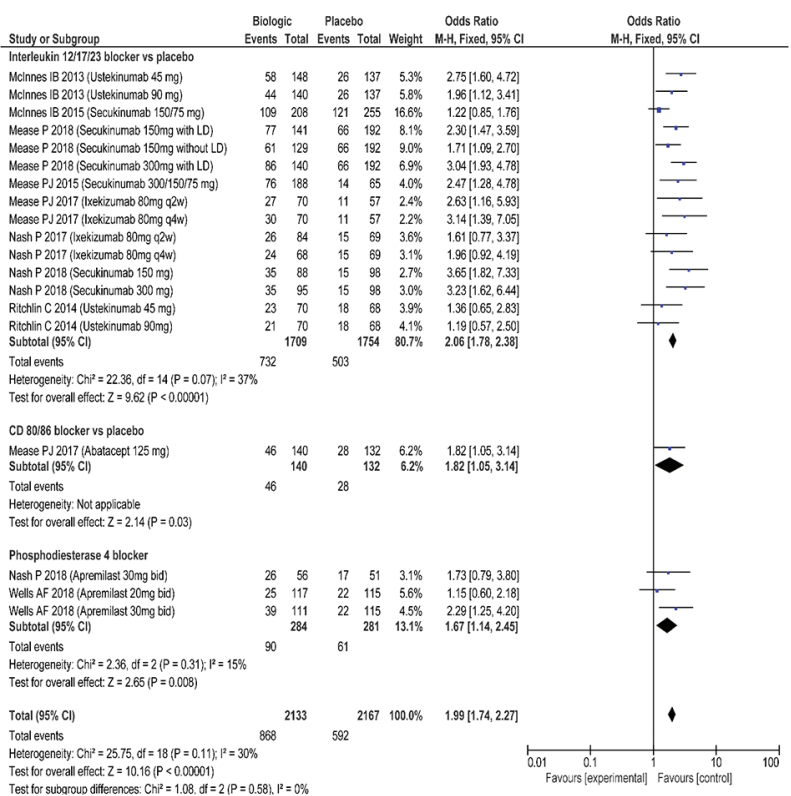

Figure 1. Risk estimates of resolution of enthesitis 


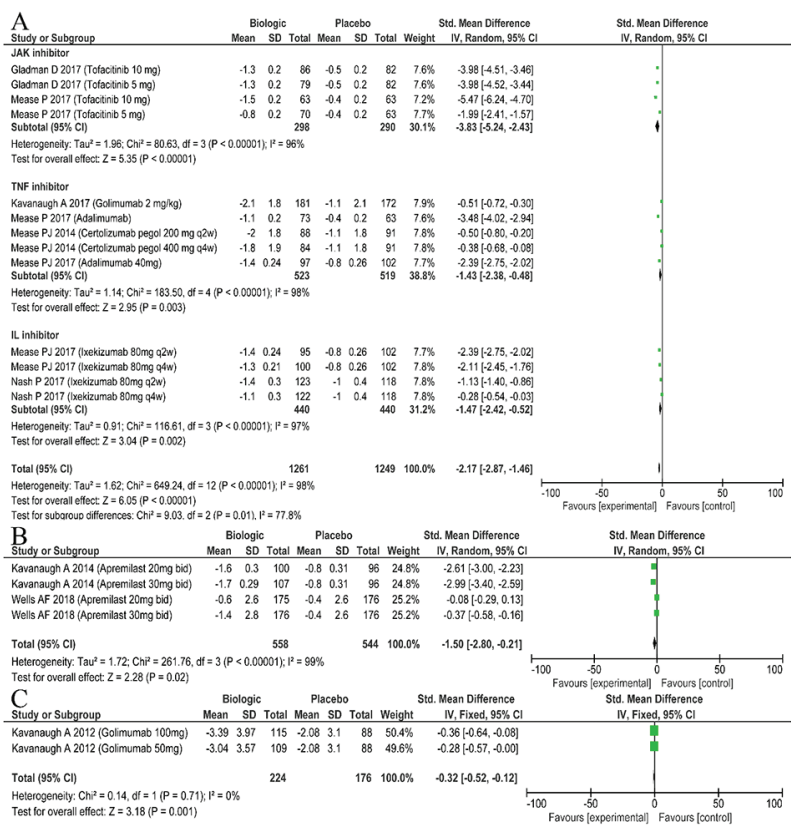

Disclosure of Interests: None declaredDOI: 10.1136/annrheumdis-2019eular.7049

Figure 2. Standardized mean difference of different enthesitis score

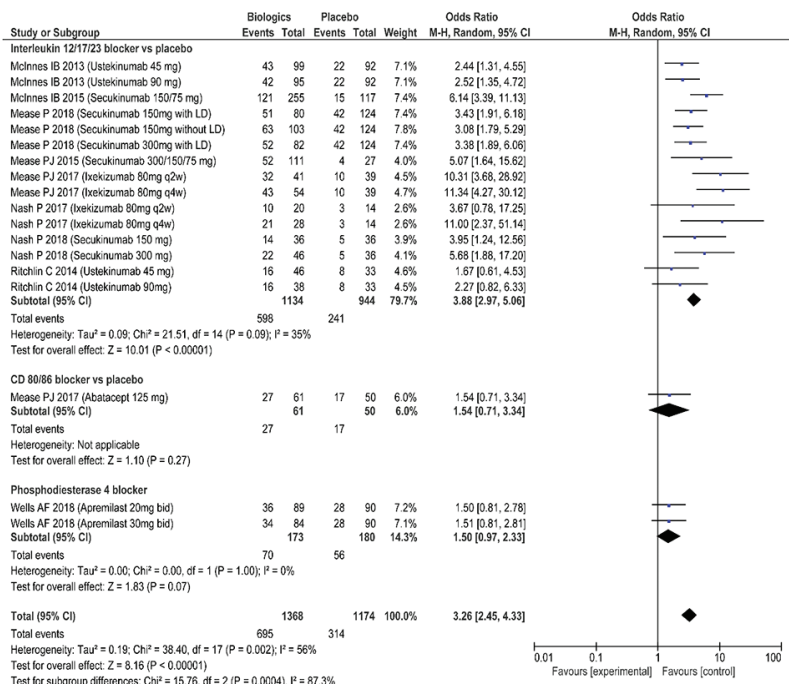

Test

Figure 3. Risk estimates of resolution of dactylitis

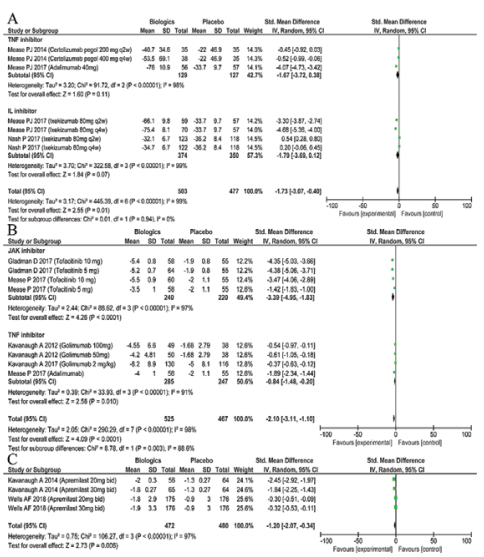

Figure 4. Standardized mean difference of different dactylitis score 